\title{
VARIATIONS IN THE BREAKABILITY OF CHROMOSOMES IN MATURE SPERMATOZOA OF DROSOPHILA MELANO- GASTER AT DIFFERENT MODES OF IRRADIATION
}

\author{
K. G. LONING \\ Institute of Genetics, University of Stockholm, Stockholm, Sweden
}

\section{INTRODUCTION}

Received I 7.vi 53

IN a preceding study (Bonnier and Lüning, 1953) it was found that a higher rate of recessive lethals is induced when the irradiation is given to spermatozoa stored in impregnated females than when the irradiation is given to males. It was further demonstrated that this is not due to the irradiation per se of the females but may perhaps be due to a difference in the state of the spermatozoa when within the seminal receptacles of the females as compared with its state within the males. This supposition is based on analogy with differences in the state in various stages of spermiogenesis already described (Lüning, I952a and $b$ ). In these papers it is demonstrated that the breakability of the chromosomes depends on the age of the males and the stages in spermiogenesis at treatment. It was further shown that apparent gene mutations, known to be intergenic changes, vary as the rate of breaks while other gene mutations, visibles and recessive lethals, may vary but not as much as the rate of breaks. From these data it was concluded that there exist both intra- and intergenic changes and that recessive lethals are of both types. The rate of intragenic changes did not seem to be changed in spermiogenesis. Hence the difference in state may be confined to the breakability of the chromosomes with a consequent increase in the rate of intergenic changes.

The higher rate of recessive lethals in spermatozoa irradiated in impregnated females versus in males may be due to an increase in intra- and/or intergenic changes. As the existence of intragenic changes can be proved only in an indirect way one must first test the occurrence of intergenic changes in spermatozoa irradiated in impregnated females versus in males. The present study deals with this analysis.

\section{TECHNIQUE}

When investigating the problem of the different states of the spermatozoa in spermiogenesis two types of aberrations both due to intergenic changes were used, viz. hyperploid males, deficient in nearly the whole paternal X-chromosome except the extreme tip and probably the centromere region (Lüning, 1952a), and yellow mutations in the $s c^{\mathrm{S1}} B$ InS w $s^{8}$ (Muller-5, M5) chromosome which according to Belgovsky (1938, 1939) are due to minute rearrangements (Lüning, 1952b). Among the yellow mutations there appeared cases in which parts only were yellow -so-called fractionals. These aberrations were of special interest to Dr Bonnier 
and as our problems were somewhat dissimilar we publish the results separately. In this paper the fractionals are included in the tables but will not be further discussed.

By using these two types of aberrations induced in spermatozoa irradiated in impregnated females or in males it is possible to examine the rates of intergenic changes in the two cases.

Following this principle $y w s n$ females have been mated to $M_{5}$ males either before or after irradiation. Among the offspring from these crosses there appeared yellow females (full and fractionals) and hyperploid males which were easily recognisable. To ensure that the results obtained were not due to some special features of the $M_{5}$ stock the experiment was repeated with $y w s n$ females mated to Canton $S$ males. The result of the latter experiment led to analysis of the offspring from Canton $S$ males mated to $y$ ac scpn sn females. This in its turn led to another experiment with $y$ ac sc pn $s n$ females mated to $M_{5}$ males.

In a fifth group of experiments the rate of induced losses of $\mathrm{X}$ - and $\mathrm{Y}$-chromosomes was studied when the spermatozoa were irradiated in the impregnated females and in the males. A special technique was developed in this experiment making use of a Y-chromosome containing a small part of an X-chromosome, viz. $s c^{8} r$, kindly put to my disposal by Dr Muller. This chromosome contains the wild type allele of the yellow locus giving males with $y w s n$ alleles in the X-chromosome the phenotype "white singed" with wild type body colour. In these experiments $y w s n$ females (known to be free from extra Y-chromosomes) were mated to $M_{5}: s c^{8} r$ males. Among the offspring there appeared $\mathrm{XO}$ males classifiable as $y w s n$ among the normal $\mathrm{XX}$ and $\mathrm{XY}$ offspring with wild type body colour. This technique will be further discussed below.

It was previously shown (Lüning, 1952a) that the rate of chromosome breaks induced in mature spermatozoa was about the same when 2-3 or 6-7 days old males were irradiated, but lower if the males were 0-1 or I-2 days old. For that reason the males were chosen which were 2-3 days old when first mated or 2-4 days old when irradiated. This is best elucidated by an example from an experiment consisting of three modes of irradiation, males only (series $M$ ), virgin females and males (series $\mathrm{vF}-\mathrm{M}$ ) and impregnated females (series $\mathrm{iF}-\mathrm{M}$ ) : 2-3 days old males were mated to females during 24 hours. Then they were etherised and irradiated together thus ensuring that spermatozoa in males and in impregnated females got the same dose. Under the same beam there was a separate group of virgin females. Immediately after irradiation the females and males were separated. The impregnated females were placed in vials without males (series iF-M). The males were divided into two lots, one lot was mated to the irradiated virgin females (series $\mathrm{vF}-\mathrm{M}$ ) and the other lot to non-irradiated virgin females (series $\mathrm{M}$ ). In series $\mathrm{M}$ and $\mathrm{vF}-\mathrm{M}$ the males were never allowed to stay with the females more than a maximum of 6 days. In some experiments they were discarded already one day after mating began. By this mating and irradiation technique one could be sure that equivalent spermatozoa were used in the different series.

In the first part of the investigation the irradiations were made at the Radiophysical Institute by means of a Siemens Stabilivolt apparatus of $155 \mathrm{kV}, 6 \mathrm{~mA}$ and I mm. Al. In the second part, our new Skandia intensive apparatus was used, operated at $170 \mathrm{kV},{ }_{1} 5 \mathrm{~mA}$ with an inherent filtration equivalent to $2 \mathrm{~mm}$. Al. The dose was $3000 \mathrm{r}$ given in $6 \mathrm{~min}$. in both apparatuses. Stocks and cultures were reared on yeast suspension as described by the author (1952a). They were kept in the incubator at $25^{\circ} \pm 1^{\circ} \mathrm{C}$.

\section{THE EXPERIMENTS}

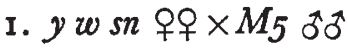

As the purpose of the present study was to investigate the mechanism underlying the higher rate of recessive lethals in spermatozoa 
irradiated in impregnated females versus in males, the same stocks were used in the first analysis of the intergenic changes (yellow mutations and hyperploid males) as in the previous study on recessive lethals. The three modes of irradiation used were spoken of above and also at the head of table I, where the results are presented. Each series is a summation of two or three experiments carried out at different periods in late 1952 and early 1953 . There was no difference in the rate of full yellow mutations and hyperploid males between the experiments in each series. For that reason only the pooled data of each series is given in table $\mathrm{I}$.

TABLE I

Offspring from crosses of $\mathrm{y}$ w $\mathrm{sn}+\% \times \mathrm{M}_{5} \delta^{\star} \delta^{*}$, mated at an age of 2-4 days. In the first series males only were irradiated, series $M$. In the second series both the males and the virgin females were irradiated, series vF-M. In the third series the females were irradiated after impregnation, series $i F-M$. Series $M$ consists of 2 experiments carried out at different times, series $v F-M$ of 3 experiments and series $i F-M$ of 2 experiments. One experiment in series $M$ was carried out parallel to one in series vF-M. Another in series $v F-M$ was carried out parallel to one in series $i F-M$. There do not exist any differences, as checked by $x^{2}$, among the different experiments in each series as concerns full yellow mutations and hyperploid males. For that reason there are given the totals only of each series. The dose was $3000 \mathrm{r}$.

\begin{tabular}{|c|c|c|c|c|c|c|c|}
\hline \multirow{2}{*}{ Series } & \multirow{2}{*}{$\begin{array}{c}\text { Total } \\
\text { offspring } \\
\text { from X- } \\
\text { carrying } \\
\text { spermatozoa }\end{array}$} & \multicolumn{2}{|c|}{ Yellow } & \multicolumn{2}{|c|}{$\begin{array}{c}\text { Fractional } \\
\text { yellow }\end{array}$} & \multicolumn{2}{|c|}{$\begin{array}{l}\text { Hyperploid } \\
\text { males }\end{array}$} \\
\hline & & abs. $n r$. & per $10^{4}$ & abs. nr. & per $10^{4}$ & abs. nr. & per $10^{4}$ \\
\hline $\mathbf{M}$. & 40,627 & 77 & 19 & 12 & 3 & 41 & 10 \\
\hline vF-M & $43,06_{1}$ & 97 & 23 & 24 & 6 & $3^{8}$ & 9 \\
\hline iF-M. & 19,269 & 53 & 28 & 19 & 10 & 38 & 20 \\
\hline
\end{tabular}

A heterogenity test on the pooled rates of full yellow mutations and hyperploid males in the three series gives $\mathrm{P}=0 \cdot 00 \mathrm{I}$. $\mathrm{A}$ comparison between series $\mathrm{M}$ vs. series $\mathrm{vF}-\mathrm{M}$ gives $0.70>\mathrm{P}>0.50$, and series $\mathrm{M}$ and series $\mathrm{vF}-\mathrm{M}$ vs. series $\mathrm{iF}-\mathrm{M}$ gives $\mathrm{P}<0{ }^{\circ} \circ \mathrm{oo}$. A comparison of the yellow mutations in series $\mathrm{M}$ and $\mathrm{vF}-\mathrm{M}$ vs. series $\mathrm{iF}-\mathrm{M}$ gives $0 \cdot 10>\mathrm{P}>0 \cdot 05$. A similar comparison of hyperploid males gives $\mathrm{P}<0.00 \mathrm{I}$. As the rates of both yellow mutations and hyperploid males vary in the same direction we may conclude that there is induced a higher rate of intergenic changes in spermatozoa irradiated in females than in males.

\section{2. $y w$ sn 우우 $\times$ Canton $S \widehat{\delta}{ }^{\star}$}

In order to study if the increased rate of intergenic changes obtained in spermatozoa irradiated within impregnated females versus in males was a peculiarity in the $M_{5}$ stock the experiments were repeated 
with the Canton $\mathrm{S}$ stock. The result of the three series is presented in table 2. The use of the Canton S stock may also give some indications of a possible effect on intragenic mutations as yellow mutations in the wild type stock are supposed to be mostly due to intragenic changes (Lüning, 1952b). As is seen in table 2 the rate of yellow mutations is in fact lowest in series iF-M. There is thus no indication of an increased rate of intragenic changes. The rate of white mutations which (according to the author, $1952 b$ ) are due to both intra- and intergenic changes is, however, significantly $\left(\mathrm{P}=0.00 \mathrm{I}\right.$ by $\chi_{\mathrm{c}}^{2}$ test $)$ higher in series iF-M than in series $M$. Also the singed mutations

\section{TABLE 2}

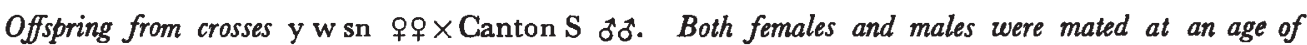
2-4 days. The same series were carried out as in table $I$. In series $M$ is included two experiments carried out at different times. One of them was parallel to series $v F-M$ and series $i F-M$. There were no differences between the two experiments in series $M$, as checked by $\chi^{2}$, for that reason they were pooled in the table. The new fractional mutations which appeared with about the same frequency in the three series are figured as full mutations in the table. White variegated mutations are not listed among white mutations.

\begin{tabular}{|c|c|c|c|c|c|c|c|c|c|c|c|}
\hline \multirow{2}{*}{ Series } & \multirow{2}{*}{$\begin{array}{c}\text { Total } \\
\text { offspring } \\
\text { from } \\
\text { X-carrying } \\
\text { spermatozoa }\end{array}$} & \multicolumn{2}{|c|}{ Yellow } & \multicolumn{2}{|c|}{ White } & \multicolumn{2}{|c|}{ Singed } & \multicolumn{2}{|c|}{$\begin{array}{l}\text { Gynandro- } \\
\text { morphs }\end{array}$} & \multicolumn{2}{|c|}{$\begin{array}{l}\text { Hyperploid } \\
\text { males }\end{array}$} \\
\hline & & $\begin{array}{l}\text { abs. } \\
\text { nr. }\end{array}$ & $\begin{array}{l}\text { per } \\
\text { 10 }\end{array}$ & $\begin{array}{l}\text { abs. } \\
\text { nr. }\end{array}$ & $\begin{array}{l}\text { per } \\
\text { 10 }\end{array}$ & $\begin{array}{l}\text { abs. } \\
\text { nr. }\end{array}$ & $\begin{array}{l}\text { per } \\
{ }_{10}^{4}\end{array}$ & $\begin{array}{l}\text { abs. } \\
\text { nr. }\end{array}$ & $\begin{array}{l}\text { per } \\
\text { 10 }\end{array}$ & $\begin{array}{l}\text { abs. } \\
\text { nr. }\end{array}$ & $\begin{array}{l}\text { per } \\
\text { 10 }\end{array}$ \\
\hline $\mathbf{M}$ & 78,347 & 17 & 2 & 23 & 3 & 12 & 2 & 50 & 6 & 50 & 6 \\
\hline vF-M & $40,25 \mathrm{I}$ & 8 & 2 & I 5 & 4 & 7 & 2 & 34 & 8 & 26 & 6 \\
\hline iF-M & 27,186 & 4 & I & 22 & 8 & 8 & 3 & 22 & 8 & 35 & 13 \\
\hline
\end{tabular}

showed an increase, although it is not significant. The rates of gynandromorphs seem to be uninfluenced by the different modes of irradiation. This agrees with the result obtained by the author (1952a) when treating various stages in spermiogenesis. The rates of hyperploid males show the same variation as that observed in the series with $M_{5}$ males. Hence we may conclude that the increase rate of intergenic changes in spermatozoa treated within impregnated females versus in males was not a peculiarity to the $M_{5}$ chromosome but appeared also in the wild type chromosome used, Canton S. In an addendum to Bonnier and Lüning (1953) it was shown that the rate of recessive lethals was higher in $\mathrm{iF}-\mathrm{M}$ type than in M-type of irradiation of Canton S spermatozoa.

\section{3. y ac sc pn sn 우우 $\times$ Canton $S$ ठૈす}

The strong increase in the rate of white mutations in series $\mathrm{iF}-\mathrm{M}$ in table 2 seemed strange in comparison with the moderate increase in the rate of hyperploid males, the more so because the rate of white 
mutations had been shown to vary with the stages in spermiogenesis but not as much as the rate of breaks (Lüning, 1952b). One possible explanation of the high rate of white mutations is a random variation due to the small absolute number. Another explanation is a localised breakability in the white region. In order to test this the experiment described in section 2 was repeated using females with other marker genes, viz. $y$ ac sc pn sn. Any localised increase in the rate of intergenic changes in the white region would be detected by an increase in the rate of hyperploid males phenotypically $s n$ compared to $p n s n$ hyperploid males in which the left break was to the left of $p n$ at locus $0 \cdot 8$.

TABLE 3

Offspring from crosses y ac sc pn sn $\$ 9 \times$ Canton $\mathrm{S} 0^{*} 0^{*}$. Both females and males were mated at an age of 2-4 days. The two series $M$ and iF-M were carried out parallelly. The hyperploid males were of two phenotypic classes, viz. pn sn and sn.

\begin{tabular}{|c|c|c|c|c|c|c|c|c|c|c|c|c|}
\hline \multirow{3}{*}{ Series } & \multirow{3}{*}{$\begin{array}{c}\text { Total } \\
\text { offspring } \\
\text { from } \\
\text { X-carrying } \\
\text { spermatozoa }\end{array}$} & \multirow{2}{*}{\multicolumn{2}{|c|}{ Yellow }} & \multirow{2}{*}{\multicolumn{2}{|c|}{ Singed }} & \multirow{2}{*}{\multicolumn{2}{|c|}{$\begin{array}{l}\text { Gynandro- } \\
\text { morphs }\end{array}$}} & \multicolumn{4}{|c|}{ Hyperploid males } & \multirow{3}{*}{$\begin{array}{c}\text { Total } \\
\text { per } \\
10^{4}\end{array}$} \\
\hline & & & & & & & & \multicolumn{2}{|c|}{$p n s n$} & \multicolumn{2}{|c|}{$s n$} & \\
\hline & & $\begin{array}{l}\text { abs. } \\
\text { nr. }\end{array}$ & $\begin{array}{l}\text { per } \\
10^{4}\end{array}$ & $\begin{array}{l}\text { abs. } \\
\text { nr. }\end{array}$ & $\begin{array}{l}\text { per } \\
10^{4}\end{array}$ & $\begin{array}{l}\text { abs. } \\
\text { nr. }\end{array}$ & $\begin{array}{l}\text { per } \\
10^{4}\end{array}$ & $\begin{array}{l}\text { abs. } \\
\text { nr. }\end{array}$ & $\begin{array}{l}\text { per } \\
10^{4}\end{array}$ & $\begin{array}{l}\text { abs. } \\
\text { nr. }\end{array}$ & $\begin{array}{l}\text { per } \\
10^{4}\end{array}$ & \\
\hline $\mathbf{M}$ & 29,862 & 4 & I & 6 & 2 & 12 & 4 & 26 & 9 & 4 & $\mathbf{I}$ & 10 \\
\hline iF-M & 32,278 & 7 & 2 & 10 & 3 & 23 & 7 & 59 & 18 & 9 & 3 & 21 \\
\hline
\end{tabular}

This experiment consisted of two series only, viz. M and iF-M. The result is presented in table 3 . There is no indication of an increase in the intergenic changes in the white region compared to the region to the left of $p n$. There was, however, a difference in the total rate of hyperploid males in table 3 as compared to that in table 2. Males of the same stock have been irradiated and mated to females of different stocks. The cause of the higher rate of hyperploid males in the experiment in table 3 is not due to a higher viability of individuals having a greater part of the distal end of the paternal $\mathrm{X}$ chromosome than in the experiment in table 2. This result suggested a fourth series of experiments, viz. y ac sc pn sn females mated to $M_{5}$ males.

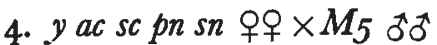

Besides studying the rates of hyperploid males induced in $M_{5}$ spermatozoa fertilising y ac sc pn sn eggs after different modes of irradiation it was of interest to Dr Bonnier to study the dependence of fractional yellow mutations of the time from irradiation to fertilisation For that reason in the series where virgin females and males were treated the females were mated either immediately after irradiation or were stored 7 days without males before mating. As 
a check the males in the series with irradiation of males only were mated to 2-4 and 9-I I days old females. In the series in which impregnated females were irradiated 2-4 days old females only were used. As regards the full yellow mutations and hyperploid males no difference was found between the two ages of females. For that reason they are combined in table 4 .

A comparison of the yellow mutations shows no significant difference, $0.50>\mathrm{P}>0.30$ between the three series. The rate of hyperploid males is, however, significantly higher in series iF-M than in series $\mathrm{M}$ and vF-M, $0.05>\mathrm{P}>0.02$. Comparing the rates of hyperploid

TABLE 4

Offspring from crosses y ac sc pn sn $ᄋ+\uparrow \times \mathrm{M}_{5}$ tot. In series $M$ the males were irradiated at an age of 2-4 days and mated to 2-4 or 9-II days old females. In series $v F-M$ the males were irradiated at an age of 2-4 days and mated to females (irradiated at an age of 2-4 days) either immediately or one week after treatment of the latter. In series $i F-M$ the females were mated at an age of 2-4 days and irradiated when impregnated. The main part of the three series was carried out parallelly. Later was added data to series $v F-M$ and $i F-M$. There was no heterogenity between the experiments within the different series, as checked by $\chi^{2}$.

\begin{tabular}{|c|c|c|c|c|c|c|c|}
\hline \multirow{2}{*}{ Series } & \multirow{2}{*}{$\begin{array}{c}\text { Total } \\
\text { offspring } \\
\text { from } \\
\text { X-carrying } \\
\text { spermatozoa }\end{array}$} & \multicolumn{2}{|c|}{ Yellow } & \multicolumn{2}{|c|}{$\begin{array}{l}\text { Fractional } \\
\text { yellow }\end{array}$} & \multicolumn{2}{|c|}{$\begin{array}{l}\text { Hyperploid } \\
\text { males }\end{array}$} \\
\hline & & abs. $\mathrm{nr}$. & per $10^{4}$ & abs. nr. & per $10^{4}$ & abs. nr. & per $10^{4}$ \\
\hline $\mathbf{M}$ & 19,243 & 56 & 29 & 6 & 3 & $4^{I}$ & $2 I$ \\
\hline vF-M & 36,738 & 87 & 24 & I 5 & 4 & 76 & $2 \mathrm{I}$ \\
\hline iF-M . & 26,723 & 78 & 29 & 9 & 3 & 77 & 29 \\
\hline
\end{tabular}

males in tables I and 4 one sees that the rate is higher in all series in table 4 . It is consequently of no importance that the females were irradiated in some series and not in others. A possible cause of this difference will be discussed below.

\section{5. $y$ w sn 우우 $\times M_{5} ; s c^{8} \Upsilon$ ỡ}

In the preceding sections it has been demonstrated that a higher rate of rearrangements is induced in spermatozoa irradiated in impregnated females than in males. This difference could be due either to a different rejoinability of broken ends or to induction of different rates of breaks in the three modes of irradiation. It was consequently of interest to discriminate between these two possible causes. Such an analysis must be based on the rate of breaks which remain unjoined since the preceding experiments were based on rejoined broken ends.

Muller (I940) and Pontecorvo (I942) showed that the rate of 
losses of $\mathrm{X}$ - and $\mathrm{Y}$-chromosomes increased linearly with the dose and they suggested that this was due to single breaks whose ends did not combine but remained unjoined until splitting when there was a sister union giving one dicentric chromosome and one acentric fragment which were likely to be lost in the nest cell division. Hence a study of losses of $\mathrm{X}$ - and $\mathrm{Y}$-chromosomes would give a measure of the rate of breaks which remain unjoined in the different modes of irradiation.

Before discussing the technique and results of the experiments we ought to consider a priori what types of result we may obtain according to the two hypotheses proposed above.

I. Supposing that the same rate of breaks is induced by the three modes of irradiation but that in one series (iF-M) the rate of rearrangements is greater than in the other two ( $M$ and $\mathrm{vF}-\mathrm{M}$ ) one must expect that the rate of breaks which remain unjoined and/or restitute in the original order would decrease.

IA. If it is further supposed that it is merely a matter of chance if broken ends will recombine or remain unjoined one would, in this case, expect a lower rate of $\mathrm{X}$ - and $\mathrm{Y}$-chromosome losses in series iF-M than in series $M$.

IB. If it is supposed that different kinds of breaks are induced as Kaufmann and Wilson (I 949) suggested, viz. complete and potential where the former eventuate in sister chromatid union with a subsequent elimination of the chromosome broken; and the ends of potential breaks joined in the original or in a new order, one would not expect any considerable difference in the rate of $\mathrm{X}$ - and $\mathrm{Y}$ chromosome losses in series iF-M and $M$. The existence of the two classes of breaks, complete and potential, has, however, not been verifiable by me (1952c) when comparing the different types of aberrations studied in various stages of spermiogenesis.

2. Supposing that the rate of induced breaks is higher in series iF-M than in series $M$ and $v F-M$ one would expect an increase in the rate of unjoined breaks which will be detected by an increase in the rate of losses in $\mathrm{X}$ - and $\mathrm{Y}$-chromosomes in series $\mathrm{iF}-\mathrm{M}$ versus series $\mathrm{M}$.

In order to discriminate between the two hypotheses discussed under I and 2 the following technique was worked out :

$y w s n$ females which were guaranteed to be free from extra Y-chromosomes were used. This was ensured by keeping the $y w s n$ stock with males having the $s c^{8} r$ chromosome. These males are phenotypically $w s n$. They were mated to $y w s n$ females for several generations. If there appear XXY females they are phenotypically $w s n$ and thus when using females phenotypically $y w s n$ they must be free from extra $\mathrm{Y}$-chromosomes. These females were mated to $M_{5} ; s c^{8} r$ males. The normal $F_{1}$ offspring is non-yellow. Losses of the paternal $\mathbf{X}$ or of the Y-chromosome manifest themselves as XO males, phenotypically $y w s n$ and are thus easily distinguishable from the rest of the offspring. As $\mathrm{XO}$ males are due to losses of $\mathrm{X}$ - or $\mathrm{Y}$-chromosomes both females and males are counted and the rate of XO males per total offspring is calculated. In this experiment only two series were carried out, series $\mathbf{M}$ and series iF-M. 
The result (table 5 ) is significantly in favour of the hypothesis of an increased rate of breaks induced in spermatozoa irradiated in impregnated females as compared with males.

\section{COMPARISON OF FULL YELLOW MUTATIONS AND HYPERPLOID MALES IN THE PRECEDING EXPERIMENTS}

In the first four groups of experiments presented it has been shown that when spermatozoa were irradiated in impregnated females a higher rate of rearrangements was induced than when irradiated in the males. When comparing the rates of hyperploid males one sees that differences exist between the various types of mating with each mode of irradiation. In order to facilitate a comparison the rates of hyperploid males and yellow mutations (in the $M_{5}$ chromosome) are combined in table 6.

TABLE 5

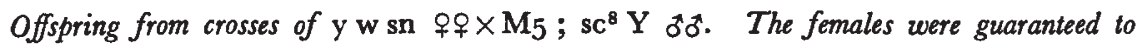
be free from extra $Y$-chromosomes by a special technique described in the text. Both females and males were mated at an age of 2-4 days. The two series $M$ and $i F-M$ were carried out parallelly. Elimination of the paternal $X$ - or $Y$-chromosome gave rise to $X O$ males, phenotypically $\mathrm{y} w \mathrm{sn}$, distinguishable from the normal $X Y$ males, which were phenotypically $\mathrm{w}$ sn as the $Y$ chromosome is a $\mathrm{sc}^{8} \mathrm{Y}$, containing the normal yellow allele. Both females and males were counted as $X O$ males were result of elimination of $X$ - or $Y$-chromosomes.

\begin{tabular}{|c|c|c|c|c|c|}
\hline \multirow{2}{*}{ Series } & \multirow{2}{*}{$\begin{array}{l}\text { Total males } \\
\mathrm{XY} \text { and } \mathrm{XO}\end{array}$} & \multirow{2}{*}{$\begin{array}{l}\text { Total } \\
\text { females }\end{array}$} & \multirow{2}{*}{$\begin{array}{c}\text { Total } \\
\text { offspring }\end{array}$} & \multicolumn{2}{|c|}{ XO males } \\
\hline & & & & abs. $n r$. & Per cent. \\
\hline & 4,774 & 5,226 & 10,000 & 82 & 0.82 \\
\hline iF-M. & 2,168 & 2,533 & 4,701 & 62 & $1 \cdot 32$ \\
\hline
\end{tabular}

First studying the rates of full yellow mutations induced in $M_{5}$ chromosomes in the two types of matings a difference is observed in series $M$ only where a $\chi_{0}^{2}$ test gives $0.02>P>0.01$. In the other two series the rates are about the same when comparing within each series. The high rate of yellow mutations in series $\mathbf{M}$ when $y$ ac sc pn sn females were mothers has no correspondence in the rate of hyperploid males when compared to the rates in series $\mathrm{vF}-\mathrm{M}$. It is not possible at present to explain this discrepancy.

The rates of hyperploid males will now be compared :

I. Comparing the rate of hyperploid males induced in $M_{5}$ chromosomes versus in Canton S X-chromosomes in the offspring from $y w s n$ females there is a significantly higher rate in the $M_{5}$ chromosome than in the Canton S X-chromosome (series $\mathbf{M}$ and vF-M).

2. The same comparison as in $I$, but in the offspring from $y$ ac sc pn sn females give the same significant result as in I (series $\mathbf{M}$ ). 
3. Comparing the rates of hyperploid males induced in Canton $\mathrm{S}$ $\mathrm{X}$-chromosomes in the offspring from $y w s n$ females versus from $y$ ac sc pn sn females there is a significantly higher rate in the latter than in the former (series $\mathbf{M}$ ).

4. The same comparison as in 3 but in $M_{5}$ chromosomes gives a significantly higher rate of hyperploid males in the offspring from $y$ ac sc $p n$ sn females than from the $y w$ sn females (series $M$ and $\mathrm{vF}-\mathrm{M}$ ).

The differences in the rates of hyperploid males in the offspring from $y$ ac sc pn $s n$ females versus $y w$ sn females are independent of irradiation of the females in some series. We may thus conclude that there are some kind of differences between the two types of females used as regards the probability of occurrence of hyperploid males, deficient for nearly the whole paternal X-chromosome.

In some earlier experiments (Lüning, 1952a) a difference in the

TABLE 6

The rates of hyperploid males from tables $I-4$ and of yellow mutations from tables $I$ and 4

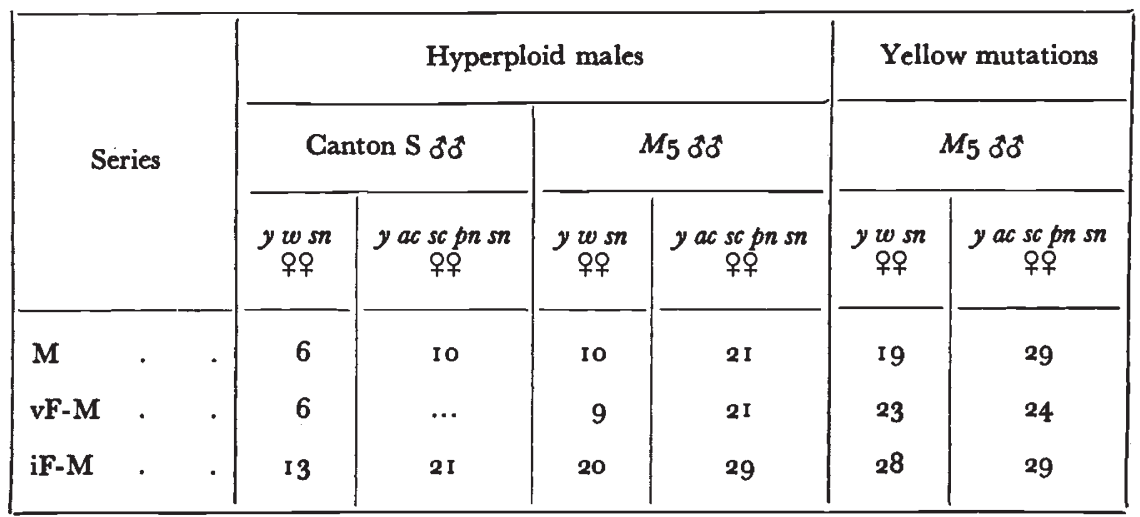

Comparing yellow mutations in series $\mathrm{M} \quad . \quad . \quad . \quad \chi_{\mathrm{c}}^{2}=5.60 .02>\mathrm{P}>0.0 \mathrm{I}$ Comparing hyperploid males :

Series M+vF-M with $y$ w sn mothers; Canton S vs. $M_{5} \chi_{\mathrm{c}}^{2}=5.50 .02>\mathrm{P}>0.01$ Series $M$ with y ac sc pn sn mothers : Canton S vs. $M_{5} . \chi_{0}^{2}=9.50 .01>P>0.001$ Series $M$ with Canton S fathers : y $w$ sn vs. y ac sc pn sn. $\chi_{\mathrm{c}}^{2}=3.50 .05>\mathrm{P}>0.02$ Series M+vF-M with $M_{5}$ fathers : y w sn vs. $y$ ac sc $p n$ sn $\chi_{\mathrm{c}}^{2}=30.6 \mathrm{P} \ll 0 \cdot 00 \mathrm{I}$

rates of hyperploid males was used as indicating a difference in the rates of breaks. By analogy we may suggest that the rates of breaks, available for rearrangements, might be influenced in some way by the eggplasm. If this was true we would expect a corresponding increase in the rates of yellow mutations in the $M_{5}$ chromosome. Of the three series it was shown above that there is a true difference in one only. In all series taken together there is not a significant difference, $\chi^{2}$ test gives $0 \cdot 10>\mathrm{P}>0 \cdot 05$.

Another fact that speaks against the present hypothesis is the following: Bonnier and Lüning (195I) demonstrated that the rate of hyperploid males was proportional to (dose) $)^{\mathbf{1 . 5}}$. If now the 
proportion of broken ends taking part in rearrangements is higher when in $y$ ac sc pn sn eggs than in $y w$ sn eggs one would a priori expect that the increase in the rate of breaks in series $\mathrm{iF}-\mathrm{M}$ versus series $\mathbf{M}$ and $\mathrm{VF}-\mathrm{M}$ would more strongly increase the rate of hyperploid males in experiments with y ac sc pn sn mothers than in those with $y w s n$ mothers. This is not the case as is seen from comparisons of the ratio of hyperploid males in series iF-M versus series $M$ and $v F-M$ in the four groups of experiments presented in table 6 . There was instead a lower increase when $M_{5}$ males were used. Hence it is not probable that the differences in the rates of hyperploid males are due to differences in the ratio of broken ends which take part in rearrangements or restitute in the original order.

As the differences between the rates of hyperploid males in the various groups of experiments do not seem to be due to the influencc of the mother's genotype (nuclear or plasmic) on the proportion of recombinations in the paternal X-chromosome we may suggest that the differences under consideration are due to differential viability of the potential hyperploid males. It was supposed (Lüning, I952a) that most hyperploid males occur from two breaks in the X-chromosome, one in the distal and the other in the proximal region. The differences between the rates of hyperploid males could then be explained either by supposing that the viability of cases with a longer distal part is higher in $y$ ac sc pn sn eggs than in $y w s n$ eggs or that it is differences in the proximal (heterochromatic) regions in $y$ ac sc pn sn and $y w s n$ chromosomes or a combination of both possibilities. Comparing the rates of hyperploid males in tables 2 and 3 one sees that in table 3 the rate of cases with breaks to the left of $p n$ is higher than the total rate in table 2. The rate of cases with breaks to the left of $p n$ is low. We may thus conclude that the difference between the rates of hyperploid males from y ac sc pn sn versus y w sn mothers are not due to differences in the length of the distal region of the paternal X-chromosome included in these males. The possibility then remains that it is due to the heterochromatic region. In favour of this suggestion is the fact that in $M_{5}$ chromosomes, with both distal and proximal heterochromatic regions, a higher rate of hyperploid males is induced than in Canton S X-chromosomes. It is possible to test the influence of the proximal heterochromatic region but such an investigation is beyond our present programme.

\section{DISCUSSION}

Herskowitz (195I) suggested three different origins of recessive lethals : "point mutations, independent of breakage; breakage alone ; and position effect following rearrangement of breaks". I showed $\left(195^{2 b}\right)$ that the rates of recessive lethals induced in spermatozoa irradiated at different stages of spermiogenesis varied but not as much as the rates of breaks. For that reason $I$ concluded that recessive lethals are due to both intra- and intergenic changes. $\mathbf{M y}$ 
term intragenic changes is nearest comparable to Herskowitz's " point mutations, independent of breakage". The proportion of recessive lethals of this origin seems, however, to be higher in my material than in Herskowitz's. This discrepancy will be dealt with in a future paper.

At present we are interested in the fact that recessive lethals occur in two ways, intra- and intergenic changes, and that the proportion of them may vary. It means that a change in the rate of recessive lethals may be due to an increase in intra- and/or intergenic changes. Bonnier and Lüning (1953) showed that when spermatozoa were irradiated in impregnated females there was induced a higher rate of recessive lethals than when irradiated in males. It was consequently of interest to find out if this increase in recessive lethals was due to an increase in intra- or in intergenic changes or in both. In the preceding paragraphs it was shown that the rate of rearrangements was higher in spermatozoa irradiated in impregnated females as compared with males. It was concluded that this was due to an increased rate of breaks rather than to a different rejoinability of broken ends.

The present analysis of chromosome aberrations was based on three different types, viz. hyperploid males, yellow mutations in the M5 chromosome (minute rearrangements) and X- and X-chromosome losses. The rate of hyperploid males has been shown (Bonnier and Lüning, I95I) to increase in proportion to (dose) ${ }^{1 \cdot 5}$, i.e. (rate of breaks) ${ }^{1 \cdot 5}$. Hence it is an agreement with expectation when it is found that the rate of hyperploid males increases more than the rates of yellow mutations and X-and Y-losses, which increase linearly with the dose according to Belgovsky, (1939) and Muller, (1940). A calculation of the increase in the rate of breaks based on a comparison between the different types of aberrations would be impaired by great uncertainties. We may, however, suggest that the true increase in the rate of breaks lies between 25 and 60 per cent. These two figures are taken from yellow mutations and $\mathrm{X}$ - and $\mathrm{Y}$-chromosome losses. The corresponding variation in the rates of recessive lethals lies between Io and 25 per cent., only Gulbekian found 70 per cent. (Bonnier and Lüning, 1953). Hence the observed increase in the rate of breaks seems to be greater than that of recessive lethals. Since recessive lethals are partly dependent and partly independent of breaks we must conclude that the increase in the rate of recessive lethals is mostly due to intergenic changes. From this comparison it is impossible to exclude a minor increase in the rate of intragenic changes as well. There are, however, two sets of experiments above in which changes, supposed to be intragenic, have been studied, viz. yellow mutations in the wild type X-chromosome. There was no indication of an increased rate of these changes. Taken together the two results point in the same direction, that there is no, or only a very small, increase in intragenic changes. 
The cause of the increased rate of breaks is, however, still obscure. Several possible explanations have been discussed by Dr Bonnier in his paper. Only one further possibility will here be put forth : and this is not an explanation, it is merely putting the problem off to a point beyond which we cannot reach-at present. I demonstrated $(1952 b)$ that the rate of breaks varied with the stages of spermiogenesis treated, as well as with the age of males at treatment. The variation of the breakability with the age of males in the mature spermatozoa was not synchronised with its variation in the inverse direction in the more sensitive stages. Changes of the physiological conditions in males when ageing seemed thus to influence the various stages of spermiogenesis in a different manner. Hence perhaps the new physiological environment-the female receptacles-changes the breakability of the spermatozoan chromosomes in a similar manner. The nature of these changes is, however, still hidden. The present investigation has at least shown that the variation in sensitivity may occur in both directions : In spermiogenesis it is lowered and in impregnated females it is raised.

\section{SUMMARY}

I. The present investigation deals with an analysis of the rates of rearrangements induced in sperm of Drosophila melanogaster when irradiated in females as compared with in males.

2. There were induced significantly more hyperploid males when irradiated in impregnated females than in males. The rates of yellow mutations in the $M_{5}$ chromosome pointed in the same directon but not with the same strong significance.

3. The rate of hyperploid males is also dependent on both the paternal and maternal stocks. A possible cause of this is discussed.

4. It is concluded that more chromosome breaks are induced in spermatozoa irradiated in impregnated females than in males, and a possible cause of this is discussed.

Acknowledgment.-This investigation was supported by the Swedish Natural Science Research Council.

\section{REFERENCES}

BELGOVSKY, M. L. 1938. Influence of inert regions of chromosomes on the frequency of occurrence and type of changes in the adjacent active regions. Bull. Acad. Sci. USSR, Series Biol., 5-6, 101 7-1036. (Russian with English summary.)

BELGovsky, M. L. 1939. Dependence of the frequency of minute chromosome rearrangements in Drosophila melanogaster upon X-ray dosage. Bull. Acad. Sci. USSR, Series Biol., 2, I 59-1 70. (Russian with English summary.)

BONNIER, G. 1954. Secondary influences from X-ray irradiation on mutational processes in Drosophila melanogaster. Heredity, 8, 199-210.

BONNIER, G., AND LÜNING, K. G. I95I. Spontaneous and X-ray induced gynandromorphs in Drosophila melanogaster. Hereditas, 37, 469-487.

BONNIER, G., AND LÜNING, K. G. 1953. Sex-linked lethals in Drosophila melanogaster from different modes of X-ray irradiation. Hereditas, 39, $193-200$. 
HERSKOWITZ, I. H. 1951. The genetic basis of X-ray induced recessive lethal mutations. Genetics, $36,356-363$.

KAUFMANN, B. P., AND WILSON, K. I949. Modification of the frequency of chromosomal rearrangements induced by $\mathrm{X}$-rays in Drosophila. IV. Post-treatment with near infra-red radiation. Genetics, 34, 425-436.

LÜNING, K. G. 1952a. X-ray induced chromosome breaks in Drosophila melanogaster. Hereditas, 38, $321-33^{8}$.

LÜNING, K. G. 1952b. Studies on the origin of apparent gene mutations in Drosophila melanogaster. Acta Zool., 33, 193-207.

LÜNING, K. G. 1952c. Studies on X-ray induced mutations in various stages of spermatogenesis in Drosophila melanogaster. Alb. Bonniers, Stockholm.

MULLRR, H. J. 1940. An analysis of the process of structural change in chromosomes of Drosophila melanogaster. 7. Genet., 40, 1-66.

PONTECORVO, G. I 942. The problem of dominant lethals. 7. Genet., 43, 295-300. 